\title{
LA FUNCION PUBLICA LOCAL EN EUROPA: CARACTERES Y TENDENCIAS
}

\author{
POR \\ Vicente maria Gonzalez-haba Guisado
}

\begin{abstract}
SUMARIO: I. Radiografía de los funcionarios locales. - II. Concepciones más importantes. -III. Volumen de los efectivos locales. - IV. Composición.-V. Técnicas de integración o diferenciación. - VI. La carrera administrativa. - VII. Incidencia del poder político.-VIII. Referencia a España._IX. Conclusión
\end{abstract}

Dentro del concepto de Función Pública, entendido en su sentido más extenso y omnicomprensivo, los servidores locales constituyen un bloque que presenta unas características y ofrece unas singularidades que no siempre son bien conocidas. Pese a la importancia que la vida local tiene en las sociedades modernas, la realidad es que la Función Pública Local está menos estudiada por los autores que la Función Pública del Estado o que otros amplios colectivos al servicio de instituciones u organizaciones públicas. La dispersión del funcionariado local, la ancha gama de entidades en la que éste sirve y trabaja, la lejanía de las entidades locales de los grandes núcleos de poder, el distanciamiento cuando no el recelo o la clara hostilidad entre la Administración del Estado y la local, las estructuras muchas veces ambiguas y difuminadas de los servicios locales son entre otras algunas de las razones que obstaculizan una aproximación para un más exacto conocimiento de la Función Pública en la mayoría de los países, en lo que a su Administración Local se refiere.

La doctrina ha sido consciente de la problemática específica y singular de la Función Pública local, inscrita en el marco de unas Corporaciones Locales que, por su propia naturaleza, son diversas, variadas y heterogéneas. Por ello, todavía sigue siendo correcta la apreciación de MAHílLo SANTOS según la cual a todo el conjunto de personas que presta servicios en el área local ha podido calificársela de "mosaico", porque lo que le caracteriza son las notas de pluralidad $y$ variedad de sus componentes, tanto en el tamaño como en la importancia y matices de los diversos grupos que lo integran, lo que es consecuencia indudable, a nuestro juicio, de las notas que caracterizan a la Administración Local y que sirven para reafirmar su propia sustantividad e individualización frente a otras Administraciones Públicas, por mucho que se pretenda, y no siempre con acierto, reducirlas todas ellas a unos mismos criterios organizativos, funcionales y de regímenes «jurídico-administrativos» (JUAN MAHILLO SANTOS, La Función Pública local española y sus problemas actuales, Instituto de Estudios de Administración Local, Madrid, 1976, p. 20). 
En las palabras acabadas de transcribir se transparenta con evidencia una importante cuestión, como es la de determinar en la medida de lo posible si la Función Pública Local ofrece hoy unas líneas tendenciales de evolución que son propias de ella o si, por el contrario, su comportamiento responde a las mismas pautas y orientaciones que imperan en otros ámbitos de la Función Pública, sea estatal, institucional, regional, autonómica. En el año 1985 , JEAN-LUC BODIGUEL se preguntaba precisamente si en el continente europeo la Función Local se atiene a exigencias de especificidad y autonomía o ha de plegarse a exigencias de uniformidad y homogeneización en paralelo con las demás Funciones Públicas (JEAN-LUC BODIGUEL, "La fonction publique locale en Europe: specificité et autonomie?», Revue Fançaise d'Administration Publique, número 34, 1985 , pp. 307 y ss.). Este trabajo, que adelantaba la publicación del libro a que luego se aludirá en sus páginas referentes a la vida local, presentaba la gran interrogante que se hacen gobernantes y políticos empeñados en construir una Función Pública Local que no sea la que marche en el último lugar de las reformas emprendidas para mejorar la situación de los servidores públicos; y que no se resigne, como en el pasado, a recibir tan sólo los beneficios residuales y tardíos de los cambios introducidos en otras esferas políticas y administrativas.

\section{RADIOGRAFIA DE LOS FUNCIONARIOS LOCALES}

Como se ha apuntado ya, no son abundantes los estudios estadísticos sobre los funcionarios locales. De ahí el interés, y la actualidad del estudio sobre la Función Pública Local en Europa que se contiene, como Capítulo V, en el libro Les fonctions publiques en Europe de l'Est et de l'Ouest elaborado bajo la dirección científica de los profesores GERARD TIMSIT, Vicepresidente de la Universidad de París I, y JANUSZ LETOWSKI, Vicedirector del Instituto del Estado y del Derecho de la Academia Polaca de las Ciencias, y editado en París por el Centro Nacional de la Investigación Científica (CNRS) en 1986.

Como se dice en las primeras líneas del Capítulo mencionado, "lo local, por su posición periférica en la frontera de la Administración y de la sociedad, goza en el seno del sistema de regulación estatal de un lugar específicon; añadiéndose que el sistema local propio de cada pais «supone un personal administrativo que compone lo que se puede designar bajo el nombre de Función Pública Local». Respecto a ésta, son muchos los aspectos que merecen ser analizados y muchas las perspectivas desde las cuales se la puede contemplar, en orden a establecer comparaciones entre unos países y otros; y a extraer conclusiones que sirvan para una mejor configuración del funcionariado local en el esquema global de los empleados públicos, tanto en los países del este como del oeste europeo. 


\section{CONCEPCIONES MAS IMPORTANTES}

Prescindiendo de puntualizaciones excesivas que contribuyan a facilitar una definición de lo que es un funcionario local, importa retener un concepto lo suficientemente elástico en el que se incluya todo el personal no político de las colectividades territoriales de base. Se excluyen, por tanto, los funcionarios de servicios periféricos, los funcionarios regionales o autonómicos, los llamados funcionarios políticos, para centrar la atención en el personal, de condición estatutaria o laboral, que, en la terminología española, constituye el núcleo esencial de agentes que trabajan en los municipios y las provincias.

Como punto de partida, hay que tener muy presente que el concepto de Función Pública Local «depende estrechamente de la articulación territorial del sistema político-administrativo de cada uno de los Estados". Procede, por tanto, hacer al respecto algunas precisiones según nos enfrentemos a la exposición de la citada articulación desde un ángulo político o desde un ángulo administrativo.

La articulación territorial del sistema político conduce al diseño a dos grandes modelos de Estado. De un lado, aparecen los Estados federales «cuyas entidades territoriales que los componen participan en la elaboración de las leyes y en la revisión de la constitución federal disponiendo de una amplia autonomía para regular sus propios problemas sin disponer, sin embargo, de competencias internacionales", perteneciendo a este grupo la República Federal Alemana, Austria, Checoslovaquia y Yugoslavia. De otro, se sitúan los llamados Estados unitarios que se caracterizan «por la existencia de una voluntad política única que se impone al conjunto de los ciudadanos, los cuales, por consiguiente, están sometidos a las mismas leyes de todos los ámbitos», incluyéndose entre ellos al Reino Unido, Francia, Bélgica, Hungría y Polonia.

Algunos de los Estados unitarios de Occidente, como es el caso de los tres acabados de citar, han llevado a cabo en los últimos años diversas reformas de carácter descentralizador (Francia, país considerado como modélico en lo que al centralismo político y administrativo se refiere, es buena prueba de ello), al tiempo que han tratado de reducir el número de sus entidades locales (Bélgica ha pasado de 2.359 municipios en 1971 a 589 nuevas entidades en 1983; y Checoslovaquia, mediante una política de integración de pequeños municipios impulsada en los años sesenta, ha reducido aquéllos de 11.963 a algo más de 9.000 ).

Junto a la articulación territorial del sistema político, debe exponerse la articulación territorial del sistema administrativo, ya que ambos sistemas no son plenamente coincidentes ni se identifican 
entre sí. Ello arrastra a diferenciar dos tipos de Administraciones: las unitarias y las descentralizadas o eclatées. Las primeras se encuentran, sobre todo, en los países socialistas orientales en los que, como es el caso de Checoslovaquia, existe únicamente una Administración en la que no se distingue entre los niveles estatal y local, por lo que, en general, se puede afirmar que no se da ninguna especificidad de la Función Local en el marco de la Administración del Estado, produciéndose, por el contrario, el fenómeno de que el régimen legal de los funcionarios es el mismo que el de los demás trabajadores. Frente a la valoración y estructuración de signo unitario, que acompaña a las Administraciones de países socialistas, en Occidente funcionan Administraciones no unitarias, descentralizadas o compartimentadas, que de alguna manera proclaman o aceptan la autonomía de las colectividades locales en grados diversos, lo que induce a «admitir la existencia de una Función Pública Local y a reconocerla una cierta especificidad":

En los países occidentales, a su vez, cabe hacer nuevas matizaciones. Hay paises en los que la autonomía local está fuertemente potenciada y desarrollada hasta el extremo de que dicha autonomía se manifiesta, en el campo de la política de personal, en la diversidad de estatutos reguladores de dicho personal; así, por ejemplo, en Bélgica no hay un estatuto único para el personal local en su conjunto ni siquiera para algunas categorías del mismo. Pero hay, tambián, otros países de la Europa Occidental que, sin atacar la especificidad de la Administración Local, tratan de limitar una excesiva dispersión del estatuto o estatutos aplicables a las Funciones Públicas territoriales, buscando el aseguramiento y la defensa de una cierta uniformidad reguladora: por ejemplo, en la República Federal Alemana «el margen de autonomía dejado a los municipios en cuanto a sus decisiones que afecten al personal $y$ a sus estructuras es bastante restringido", puesto que el Derecho sobre la Función Pública casi exclusivamente emana de la Federación y los Länder, mientras que en Austria se aplican idénticos principios del citado Derecho a los funcionarios federales y locales y en Francia, con la Ley de 26 de enero de 1984, se ha asimilado el régimen jurídico del personal local al del Estado.

\section{VOLUMEN DE LOS EFECTIVOS LOCALES}

Un nuevo ángulo para considerar, científicamente, la Función Pública fiscal es el relativo a la fijación de su magnitud o volumen. Aquí entran en juego, como es obvio, los dispositivos e instrumentos estadísticos que, ciertamente, no arrojan resultados plenamente convincentes y tan sólo permiten al investigador aproximaciones más 
o menos convincentes. Si, en el ámbito nacional, las estadísticas son escasas en esta materia, las dificultades se incrementan cuando de lo que se trata es verificar contrastes entre unos países y otros, entre unas Administraciones y otras.

Como premisa general, hay que partir de que «la importancia de los efectivos varía según las competencias concedidas a las colectividades territoriales". Esta es la causa de que, comparando los casos del Reino Unido y de Francia, resulte que el volumen global de los servidores del Estado y de las entidades locales sea «sensiblemente idéntico» sólo que en proporción inversa; de forma que si Francia, en el año 1981, contaba con 2.601 .000 agentes estatales y con 725.000 agentes locales (lo que supone el $21,8 \%$ en el conjunto de toda la Función Pública), Inglaterra, en el año 1979, tenía 738.000 agentes integrantes del Civil Service y 2.351.121 agentes empleados en las entidades locales.

Las estadísticas disponibles permiten aislar algunas tendencias de interés y formular algunas afirmaciones muy significativas. En los paises orientales, la Función Pública Local tiene, en el conjunto de la Función Pública nacional, mayor peso específico que en los países de Occidente: mientras en éstos supone de un cuarto a un tercio del total (con la excepción, ya expuesta, de Inglaterra), en aquéllos alcanza o representa los dos tercios o las tres cuartas partes (caso, por ejemplo, de Polonia y Hungría). No sucede lo mismo, sin embargo, si relacionamos la Función Local con el total de la población activa, ya que la proporción es más fuerte en los países occidentales (el 10,3 por 100 en Inglaterra, el 5,4 por 100 en Bélgica, el 3,6 por 100 en Alemania Occidental y el 3,4 por 100 en Francia) que en los orientales $(0,6$ por 100 en Hungría y 0,3 por 100 en Polonia).

Otra observación a realizar es la de que los datos manejados permiten comprobar que, en algunos países (Bélgica, Francia, Hungría y Polonia), el personal local presta sus servicios en los municipios en un 75 por 100 aproximadamente, mientras que el resto trabaja en otras entidades locales de muy compleja naturaleza.

Finalmente, como constatación de un nuevo fenómeno a retener, hay que referirse al hecho, muy cargado de consecuencias de todo género, de que las estadísticas reflejan "desde hace aproximadamente dos decenios una evidente progresión" de los efectivos locales. Mientras que, en Alemania Occidental, entre 1960 y 1980, el personal comunal ha pasado de 642.000 a 920.000 efectivos, en parecido periodo en Francia se ha desencadenado un aumento en dicho personal de 356.603 a 605.000 , con unos incrementos, por tanto, del 43,3 por 100 y del 69,6 por 100 , respectivamente; en el Reino Unido, por el contrario, los aumentos han sido mucho más moderados con unas tasas de progresión del 1,2 por 100 en Inglaterra y País de Gales y del 1,7 por 100 en Escocia, lo que da «la 
impresión de un relativo estancamiento". $Y$ si comparamos el crecimiento de la Función Pública local con el de otras Funciones Públicas, los escasos datos manejados en el estudio descubren que, si en Alemania Occidental los efectivos municipales han crecido más pausadamente que los de la Federación y los Länder, aunque de manera más regular y estable, en Bélgica los aumentos han sido sensiblemente idénticos.

Las causas del crecimiento descrito ayudan a una mejor comprensión de los cambios que se están gestando en la Administración Local. Esta, impulsada por las demandas de los ciudadanos y vecinos, tiende a transformar su repertorio de prestaciones y servicios basándose en criterios de eficacia, participación y solidaridad. No es de extrañar, pues, que, en nuestros días, en el campo municipal y provincial sean determinados servicios los que vayan ocupando mayor número de efectivos a la vez que éstos sufren rebaja o reducción en otros servicios de corte más tradicional. El análisis de los procesos de cambio en Francia, Bélgica, Alemania Federal y Reino Unido viene a demostrar que, en campos como el de la salud, la medicina, la asistencia social, la cultura, la vivienda, la seguridad ciudadana, etc., se está desarrollando un creciente protagonismo de las entidades locales con el consiguiente fortalecimiento de las correspondientes estructuras burocráticas y funcionariales; todo ello en detrimento de otros sectores de actividad que se encomiendan al Estado y a los poderes centrales «Esta situación - se concluye en el estudio-- lejos de traducir una sistemática inflación de las estructuras burocráticas de los aparatos locales, muestra con evidencia, al menos para los Estados del Oeste de Europa, cuanto las Administraciones Locales más ampliamente investidas de misiones intervencionistas han relegado sus tareas administrativas tradicionales a un segundo plano y adquirido paralelamente la dimensión de verdaderas "empresas de servicio"» (lo destacado en cursiva es nuestro).

\section{COMPOSICION}

La Función Pública Local "es una población heterogénea» que puede ser examinada y radiografiada desde diferentes puntos de vista, como se verá a continuación.

Un primer parámetro a utilizar es el del grado de feminización que le caracteriza. Ya, en 1975, ALAIN PLANTEY, escribió con referencia al acceso de las mujeres a los cargos públicos que «poco a poco se abren a las mujeres todos los dominios de actividad antes reservados a los hombres: como del asalariado privado y de la empresa comercial o industrial, es el caso de la política y de la función pública", añadiendo que la sfeminización de la Administración y, en el seno de ésta, el 
mejoramiento de la situación de las mujeres son la manifestación de una de las tendencias profundas y generales de nuestra sociedad contemporánea" (ALAIN PLANTEY, Prospective de l'Etat, Centre National de la Recherche Scientifique, París, 1975, pp. 18 y ss.).

El proceso de feminización en el sector público se ha acelerado con el paso de los años. En el campo local, su Función Pública «está masivamente caracterizada por un fuerte grado de feminización", como lo demuestran las siguientes tasas: Polonia, el 72,6 por 100; Checoslovaquia, el 67 por 100; Hungría, el 60,3 por 100; Reino Unido, el 53 por 100; Bélgica, el 50,3 por 100, y Francia, el 45 por 100. Y dicha feminización todavía se acentúa más en los escalones de base que en los superiores de la Administración Local, como en el caso de Checoslovaquia, donde la feminización que alcanza las dos terceras partes del personal local de los comités nacionales sube hasta el 80 por 100 en los comités municipales.

Aunque, como acaba de explicarse, las mujeres tienden a incrementar su presencia en la Función Local «ellas no ocupan más que raramente puestos de responsabilidad». En Austria, por ejemplo, los servidores locales del sexo femenino desarrollan, por lo general, funciones básicas y elementales (secretariado, mecanografía, estenotipia, etc.) al tiempo que los destinos más cotizados son adjudicados a los hombres «aun en los pequeños municipios».

Otra constatación es que las mujeres se inclinan hacia puestos de trabajo que estén insertos en los sectores sociales de la actividad local. En Bélgica, en los centros públicos de ayuda social las mujeres ocupan las tres cuartas partes de los puestos de trabajo.

En el proceso de incremento de los efectivos locales, ya expuesto, se advierte que aquél ha afectado principaimente a las mujeres de tal manera que «una pirámide de edades por sexo revelaria, pues, para numerosos países, una gran juventud de la Función Pública femenina». Sin embargo, hay excasa presencia de los jóvenes en las dependencias locales lo que puede atribuirse a la confluencia de diversos factores como son el desarrollo de la carrera administrativa en la Administración local, que es menos brillante que la del Estado; los bajos salarios que se perciben, y, también, el escaso atractivo de la clase de trabajo a efectuar. Si a esto añadimos el que muchos empleos y ocupaciones de la Administración local están poco o nada cualificados, cuando no deficientemente remunerados, y el que en ocasiones las ofertas de trabajo tienen más un carácter «social» que propiamente laboral, se comprenderán las causas por las cuales principalmente son los adultos quienes tienden a enrolarse en la Administración Local no tanto por satisfacción en sus exigencias laborales cuanto por necesidades de trabajar al precio que sea. $Y$ aunque, en ocasiones, ingresen en la Función Local personas procedentes de otras actividades profesionales o laborales a causa de sus fracasos en los respectivos 
mercados de trabajo con el consiguiente peso de su mayor edad, ello se contrarresta no obstante con determinadas medidas adoptadas en algunos países, como Francia, para jubilar a empleados locales ingresados después de la segunda guerra mundial, lo que determinará, sin duda, un rejuvenecimiento de la Función Pública francesa.

Otro parámetro para el análisis de la composición de la Función Pública Local es el del tipo de tareas que sus componentes llevan a cabo. Las clasificaciones para ordenar aquéllas son complejas y no siempre ofrecen la suficiente claridad y sistematización. Se puede intentar una clasificación con arreglo al nivel jerárquico del personal local, o atendiendo a su cualificación (administrativos-técnicosobreros). Las estadísticas manejadas en el estudio «resultan muy heterogéneas para hacerlas objeto de un análisis profundo", por lo que sólo cabe reflejar los porcentajes atribuibles a cada pais con arreglo al criterio clasificador utilizado. Alemania Occidental (1982): administradores generalistas (funcionarios, 12,4 por 100 , y empleados, 52 por 100 ) y obreros, 35,5 por 100; Bélgica (1982): administradores generalistas (municipios, 25 por 100, y centros públicos de asistencia social, 16 por 100), técnicos especialistas (municipios, 31 por 100, y centros públicos de asistencia social, 31 por 100) y obreros (municipios, 44 por 100, y centros públicos de asistencia social, 33 por 100); Hungría (1982): administradores generalistas (funcionarios directivos, 10 por 100 , y gestores, 90 por 100); Reino Unido (1972): administradores generalistas (administradores superiores, 16 por 100 , y otros administradores, 8 por 100), técnicos especialistas, 29 por 100, y obreros, 47 por 100, y, por último, Francia (1970-1980): administradores generalistas (cuadros superiores, 3,3 por 100 , y cuadros medios, 10,8 por 100) y técnicos especialistas, del 29 por 100 al 42 por 100, según el tamaño del municipio.

Un tercer parámetro de interés es el de la duración del trabajo de los funcionarios locales. Las estadísticas arrojan cifras que no siempre son susceptibles de una valoración armónica y consecuente. Veamos algunos datos. En Bélgica, más del 90 por 100 de los servidores municipales y de los centros públicos de ayuda social cumplen su trabajo en jornada completa a diferencia de los que trabajan en las provincias, cuyo porcentaje se reduce al 76 por 100. En Alemania Occidental, un 78,5 por 100 de los efectivos municipales trabaja a tiempo completo.En Francia, una cuarta parte de los agentes comunales ocupa con carácter permanente un empleo a tiempo parcial, mientras que dicho porcentaje se reduce al 10 por 100 para los agentes departamentales. Y finalmente, en Inglaterra y País de Gales el trabajo a tiempo parcial está más extendido entre los obreros (57 por 100) que entre los empleados (13,3 por 100).

En relación con la duración del trabajo, no hay que olvidar la importante dicotomía existente en el personal local entre titulares y 
no titulares, o entre el personal estatutario (funcionarios) y laboral (obreros). Sólo algunos datos esbozan ciertas tendencias o apuntan determinadas características de la Función Pública Local. En Alemania Federal, la dualidad legalmente establecida entre funcionarios, por un lado, y empleados y obreros por otro, es más clara en la Administración Local que en la Federación y en los Länder, de modo que mientras los funcionarios predominan en éstos y aquélla, los empleados destacan en la Administración Local. Y, en Francia, el porcentaje de no titulares en esta Administración es del 35,8 por 100 , siendo más elevado en el personal que trabaja en las instituciones culturales, sociales y de higiene, así como en el personal de servicios con respecto al personal técnico y administrativo.

Un cuarto y último parámetro válido para estudiar la composición de los funcionarios locales es el que determina el nivel formación de éstos, partiendo para ello, de forma simplista, de tres niveles como son el primario, secundario y superior. En los países occidentales, la Función Local se nos presenta poco cualificada, como lo revela un dato significativo: en Francia y en el Reino Unido tan sólo un 2 por 100 de los efectivos locales tienen una formación de nivel superior. Por el contrario, en los países orientales europeos el panorama es más optimista y ofrece resultados más satisfactorios, con la excepción de Checoslovaquia.

Tras la exposición de los datos acerca de la composición de los funcionarios locales y que, como se podrá comprobar, no son ni todo lo fiables ni todo lo completos que fuera de desear, pese a las lagunas estadísticas que se detectan en el estudio, se puede al menos formular algún tipo de resultado o conclusión en los términos siguientes: "Más allá de los desajustes impuestos por los órdenes jurídicos nacionales, se diseña la imagen de una Función Pública Local cuya sociologia muy homogénea de un país a otro se caracteriza por los efectivos muy feminizados, bastante mayores y todavia insuficientemente cualificados y que representan un componente no despreciable $e$ incluso muy importante (Gran Bretaña) del conjunto de la Función Pública» (lo destacado en cursiva es nuestro).

\section{TECNICAS DE INTEGRACION O DIFERENCIACION}

Las relaciones entre la Administración Central y la Administración Local dan lugar a una serie de posibilidades que se explicitan en modelos de Función Pública Local diferenciados entre sí. Ello se comprueba si nos fijamos en las fuentes jurídicas por las que, en los diferentes países, se rigen los funcionarios locales. En efecto, si recorremos Europa descubrimos «un abanico de situaciones nacionales extremadamente diversificadas" que van desde países en los que se 
aplica un código único de trabajo a la Función Pública tanto estatal como local y que es el mismo que se aplica a los trabajadores del sector privado (Checoslovaquia, Hungría, Polonia, Bulgaria y Yugoslavia), hasta otros países que, aun proclamando la autonomía local y la especificidad de su régimen legal en cuanto a los empleados locales, buscan conseguir un estatuto uniforme para todos los funcionarios (Austria, Bélgica, Francia y Alemania Federal), pasando por otro país, el Reino Unido, en el que los empleados y servidores locales se rigen por normas negociadas con las autoridades locales y que no guardan relación alguna con las que están vigentes para la Función Pública central.

En cada país, lógicamente, en atención a sus rasgos históricos, culturales, políticos y sociales, predominan unas técnicas u otras encaminadas unas veces a conseguir la integración de la Administración Local, y por lo mismo de su Función Pública, en la órbita centralista, y otras dirigidas a establecer diferenciaciones y contrastes entre ambas Administraciones.

Por lo que se refiere a las técnicas jurídicas, la integración de esta naturaleza «es el medio privileqiado de asequrar la subordinación de los órganos locales a los órganos centrales» en el este de Europa donde el centralismo político impone una subordinación vertical de las entidades locales respecto a los órganos centrales (casos de Bulgaria, Checoslovaquia y Polonia), con la excepción de Yugoslavia, donde predomina el sistema autogestionario de los municipios. En el oeste europeo, por su-parte, los países acuden a determinadas técnicas de naturaleza jurídica para reducir o amortiguar la diferenciación de la Administración Local apelando, por ejemplo, al encuadramiento legal y reglamentario (casos de Francia y Bélgica) que persigue aproximar el régimen legal de los servidores locales al de los estatales, como se desprende del estatuto francés de 1984 de la Función Pública Territorial asentado sobre dos principios como son la unidad de toda la función pública territorial y su paridad con la estatal. Otros países occidentales, Austria entre ellos, utilizan la llamada cláusula de uniformación que impide que las autoridades provinciales que pueden legislar en materia funcionarial a nivel provincial y local lleguen a derogar las leyes y reglamentos de la Federación que son de aplicación a toda la Función Pública. Y está también el caso de Alemania Federal que, a través del instrumento del Ilamado Derecho de legislación concurrente que la Ley Fundamental otorga a la Federación, hace que los Länder sólo puedan legislar en tanto en cuanto la Federación no haga uso de sus facultades normativas.

En cuanto a las técnicas económicas, se comprende fácilmente que los países orientales europeos se apoyen sobre dispositivos de planificación y dirección para ordenar las relaciones entre el poder 
central y los poderes locales. Mientras que Checoslovaquia se apoya en la planificación para reforzar y fortalecer la integración de la Administración Local en los esquemas gubernamentales, Yugoslavia hace uso de la planificación para lograr mayores cotas de diferenciación. En los países occidentales, las colectividades locales son deficitarias en sus presupuestos, por lo que necesitan las aportaciones estatales y las ayudas financieras del poder central; de ahí, por tanto, que dichas aportaciones y ayudas tiendan a una mayor integración y cristalicen en fórmulas múltiples (subvenciones, cesión de impuestos, transferencias) que, de una manera $u$ otra, reducen la autonomia local y la supeditan a instancias superiores. Unas veces, las ayudas estatales lo son fuera del ámbito presupuestario para atender a una necesidad concreta o compensar una determinada carga, mientras otras lo que se implanta es una tutela financiera que trata de controlar el comportamiento económico y financiero de las entidades locales apara evitar que incrementen sus gastos o utilicen los recursos de forma inadecuada.

Las técnicas expuestas, sean económicas o jurídicas, actúan privilegiadamente sobre determinados dominios de la Función Pública local. El primero de ellos es la política de retribuciones, en el que "predomina la integración", sin excluir, no obstante, "una parte de diferenciación». Por ello, resulta que «la mayor parte de los gobiernos», por unos motivos o por otros, "asignan límites precisos al montante de los sueldos de los agentes de las colectividades locales». Es la situación que se advierte prácticamente en todos los países del Este «en razón del sistema unitario de Función Pública que en ellos prevalece» y en numerosos países de Occidente. Una vez más la excepción más llamativa es la de Yugoslavia, donde la fijación de las retribuciones de los trabajadores locales se verifica por medio de un acto autogestionario general de la organización de base, si bien el aumento anual queda condicionado a la aprobación por el Gobierno para efectos de control inflacionista. En Hungría, curiosamente, la Oficina Nacional de Salarios y de Trabajo fija los sueldos de los funcionarios locales y estatales sin respetar la paridad entre unos y otros, ya que los sueldos de aquéllos son inferiores $y$, además, el abanico salarial varía con arreglo al nivel territorial, siendo menor en los municipios que en otras colectividades territoriales. Por el contrario, en Austria, y también en Bélgica, los sueldos de los funcionarios municipales y provinciales son más altos que los de los servidores estatales, precisamente lo contrario de lo que acontece en Hungria, como se ha indicado, y asimismo en Francia.

Por encima de las diferencias expuestas, y más allá de peculiaridades nacionales, «parece claro que la tendencia dominante sea una armonización por la vía de una intervención creciente del Estado en este dominio" (lo destacado en cursiva es nuestro). Así se deduce de 
las variables económicas y sociales que entran en juego en esta materia, ya que la sensibilidad hacia la igualdad entre todos los servidores públicos, la crisis económica que sacude a muchos Estados, la presencia de los sindicatos en la escena burocrática, son algunas de las razones que avalan la afirmación que se acaba de transcribir.

La política de empleo es otro de los dominios en los que se dan cita la integración y la diferenciación como las dos grandes opciones en que se debate la Administración Local en la actualidad. En dicha política se equilibran, más que en otras, integración y diferenciación puesto que ambas opciones están presentes, de forma similar, en los países objeto de la investigación. En Checoslovaquia, como en otros países del Este, tanto el reclutamiento como el reparto de los agentes públicos se lleva a cabo por el Gobierno central; y también en Francia «pese a algunas disposiciones en sentido inverso, la integración es dominante», mientras que en Alemania Federal se aplican determinadas medidas que perjudican notablemente la política de empleo por parte de las colectividades locales. Como países en los que la Administración local goza de mayor capacidad a la hora de seleccionar y destinar a sus funcionarios, destacan Inglaterra $y$, de alguna manera, Bélgica y Francia.

La política de formación es, entre todas las expuestas, la que está más condicionada por las tendencias diferenciadoras. Aunque en algunos países, como Checoslovaquia y Austria, en principio la formación y el perfeccionamiento de los funcionarios locales siguen los derroteros vigentes en la Administración Central, «/a especificidad de los asuntos locales parece, sin embargo, llamar a enseñanzas diferenciadas" (lo destacado en cursiva es nuestro). Diversos países, como Hungría, Bélgica, Polonia y Francia, tratan de implantar unos métodos y sistemas de formación y perfeccionamiento que sean adecuados para los funcionarios locales que han de trabajar en ambientes muy peculiares, que deben resolver asuntos inmediatos y afectan directamente al interés de los vecinos, que han de moverse en un clima laboral a veces más tenso y crispado y que deben contar con unas cualidades humanas adaptadas a su misión profesional. $Y$, en lo que atañe a Gran Bretaña, cada autoridad local es la responsable de la formación y perfeccionamiento del personal a sus órdenes, al tiempo que en Yugoslavia las decisiones sobre estas materias son tomadas por las respectivas organizaciones de trabajo asociado.

De lo expuesto, no es sencillo extraer conclusiones definitivas y plenamente aceptadas. La dispersión de los datos y su variabilidad no permiten hacer afirmaciones globales y genéricas. En principio, hay que decir que, en ninguno de los dominios descritos, se impone totalmente la integración o la diferenciación. Más bien «domina más 
frecuentemente, en cada país, una combinación de las dos, pero tanto en el interior de cada país como en el plano global parece que las tendencias a la uniformización e incluso a la integración son las que prevalecen» (lo destacado en cursiva es nuestro).

\section{LA CARRERA ADMINISTRATIVA}

La carrera de los servidores públicos es una de las cuestiones en la que el funcionario está más interesado, ya que le permite, si está bien diseñada, ascender, promocionarse, moverse de unos puestos de trabajo a otros, pasar de un Cuerpo o Escala a otro, mejorar en su vida tanto personal como profesional, asumir funciones de mayor responsabilidad, etc.

Como ha indicado ESCUIN PALOP, «la gesitón de las carreras es una función esencial de la gestión de personal, concretándose en planes de formación y en el movimiento de funcionarios a distintos puestos", señalando a continuación que "lo que más distingue los diversos sistemas nacionales es la importancia atribuida en la progresión de las carreras a los responsables de la gestión de personal y a los propios interesados" (VICENTE M. ESCUIN PALOP, El acceso del personal y la provisión de puestos de trabajo en la Administración del Estado y de las Comunidades Autónomas, Instituto Nacional de Administración Pública, Alcalá de Henares-Madrid, 1986, p. 15).

La gestión de la carrera de los agentes locales puede ser llevada a efecto por instancias estatales o ser objeto de una descentralización, "según el grado de integración o de diferenciación de la periferia». La opción de una gestión estatal es aplicada, básicamente, en los países del Este, en los que se distingue entre órganos gestores de vocación general y órganos gestores de vocación especial. Lo que «a veces es interpretado como un reconocimiento implícito de la especifidad de los problemas comunales". En Polonia, por ejemplo, una ley de 28 de julio de 1983 ha creado la Oficina del Ministro de Administración y de Economía del Espacio que se encarga de asegurar, además de la coordinación y el control de la actividad de los órganos locales, la dirección de la política de personal. Y la otra opción, la de gestión descentralizada, encuentra su "tipo ideal", en el sentido de Weber, en el sistema británico, donde no hay ningún órgano central de gestión de personal, puesto que las colectividades locales actúan libremente a la hora de gestionar la carrera de sus empleados; y también Francia, con su ley de 26 de enero de 1984, ha preferido esta opción con la creación de los centros de gestión que han de conciliar la libertad de los rectores locales con el derecho de los funcionarios a una carrera administrativa, atribuyéndose a dichos centros amplias facultades que afectan a la citada carrera. 
Más allá de los modos o cauces de gestión de la carrera de los agentes locales se encuentra la necesidad de deslindar cuáles son los principales problemas que presenta la carrera de dichos agentes. Dos son, fundamentalmente, los aspectos a considerar: la movilidad y la motivación.

La crisis de la movilidad deriva del hecho de que, en muchos países, los agentes locales se encuentran como atrapados sin posibilidad alguna de movilidad jerárquica o de unas corporaciones a otras. Las limitaciones son muy fuertes en Bélgica, donde no hay un estatuto equivalente para todos los agentes locales $y$ donde las posibilidades de promoción, especialmente en los pequeños municipios, son más reducidas que en las esferas estatales de los Ministerios, así como en Austria, donde los agentes comunales no pueden cambiar, salvo excepciones, de categoría. En el extremo contrario, una vez más, se sitúa el Reino Unido, ya que "la gran homogeneidad de las condiciones de trabajo favorece la movilidad de las carreras que comportan frecuentemente varias afectaciones en varias colectividades locales diferentes, aunque no se asiste apenas a movimientos de personal entre las Administraciones Centrales.y el Civil Service».

La movilidad del personal guarda estrecha vinculación con la capacidad de decisión de las corporaciones locales, de tal modo que se puede decir que «la débil movilidad general del personal de la Administración Comunal es la contrapartida de la autonomía local y de su traducción jurídica». La pugna entre los rectores de la vida local y los agentes locales está abierta, ya que si aquéllos tratan, por todos los medios, de "controlar» la movilidad del personal los funcionarios buscan a toda costa amplios y mayores horizontes a su carrera administrativa para lo que apelan a las instancias supremas del Estado, reclamando una normativa moderna y actual que ampare su derecho a la movilidad a costa incluso de disminuir la autonomía local. La solución no es fácil y de ahí el inmovilismo en que muchos Estados se encuentran anclados en la actualidad en esta materia.

Junto a la crisis de la movilidad, sobresale la crisis de la motivación. Los agentes locales no están suficientemente motivados, y ello repercute en su moral profesional y en su ritmo de trabajo. Los salarios bajos, la citada carencia de movilidad, la falta de cualificación ajustada a las tareas que han de desempeñarse, son algunas de las causas que se pueden indentificar como las que desmotivan a los funcionarios. Junto a estas causas, que cabe calificar como clásicas o tradicionales, hay otros factores que inciden en la misma dirección y que derivan de la naturaleza de las funciones a cumplir. Tales son, entre otros, la realización de tareas fuera del horario, la ocupación de puestos de trabajo para los que no se tiene la necesaria capacitación profesional y técnica, el desempeño de actividades en las que no cabe potenciar y demostrar las competencias y aptitudes personales, etc. 
De todo ello «resulta un sentimiento de malestar que está en el origen de una fuerte inestabilidad de los efectivos", que, sin duda, repercute en sus niveles de rendimienteo y dedicación.

\section{INCIDENCIA DEL PODER POLITICO}

La Función Pública Local está inmersa plenamente en la vida política local y hasta ella llegan necesariamente las secuelas, las salpicaduras y las repercusiones de grupos y partidos que intervienen en aquélla. Como ha recordado recientemente SOSA WAGNER, la autonomía local no se puede reducir de modo simplista a su componente administrativo, ya que, en ella, confluyen tanto dicho componente como el de índole política (FRANCISCO SOSA WAGNER, Manual de Derecho Local, Editorial Tecnos, Madrid, 1988, p. 58). En consecuencia, pues, procede examinar de qué manera, y con qué intensidad, el poder político se proyecta sobre la Administración Local.

Las relaciones entre Administración y poder político admiten, en esencia, dos planteamientos. Uno de ellos defiende la tesis de la independencia entre ambos, apoyándose en el esquema clásico de deslindar las funciones que llevan a cabo los órganos elegidos por los ciudadanos y las que corresponden a los funcionarios, tal como sucede en Gran Bretaña y en otros países, como Alemanía Federal, Bélgica y Francia. No obstante esta visión de las cosas es utópica e irreal, ya que la separación entre los elementos políticos y los administrativos no se da tan fácilmente y no se corresponde con los hechos. De ahí que sea más correcto el otro planteamiento, que postula una interdependencia entre Administración y política, que se advierte con más rotundidad en el ámbito local que en el estatal, dando origen a una ascendente politización de la Función Pública Local a través de dos vías principales: la óssmosis entre funcionarios y elegidos y la ósmosis entre funcionarios y hombres de partido. Ambas ósmosis contribuyen a una politización, no siempre positiva, de la Función Pública Local que se ve interferida por los intereses partidistas y corre el riesgo de quedar sometida a las presiones ideológicas de unos y otros.

Las relaciones descritas sumariamente entre Administración y poder político condicionan, lógicamente, las relaciones entre funcionario local y poder político. Dos palabras sirven para precisar el alcance del tema que ahora se aborda: neutralidad y obediencia. Respecto a la primera neutralidad, el único país que exige a los agentes locales la observación de una neutralidad estricta es la Gran Bretaña, obligación que «se inscribe como el corolario del principio de la separación de funciones entre elegidos y funcionarios». En Francia, 
los servidores locales tienen idénticos derechos políticos que los estatales, reclamándoseles neutalidad y el denominado deber de reserva. Sin embargo, la exigencia de la neutralidad encuentra obstáculos difíciles de superar en la vida local, ya que el funcionario local, al tiempo que está cercano al político que gobierna la colectividad territorial correspondiente, también lo está a la gente que le habla de sus problemas, sus reivindicaciones y sus necesidades; lo que no sucede en la Administración del Estado, ya que «el que está cerca del público (el que atiende, por ejemplo, la ventanilla) está lejos de la gente». Por tanto, «la situación del agente local es muy diferente" y su trabajo ha de llevarlo a cabo en un marco donde ni la política ni las posiciones ideológicas diversas están ausentes.

La otra palabra anunciada es obediencia. Si, como se acaba de explicar, la neutralidad del funcionario local es difícil de mantener hay un riesgo permanente de que acabe incurriendo en una obediencia más o menos definida. Hay una obediencia tácita que se manifiesta después del reclutamiento, en la toma de posesión y que no tiene mayores consecuencias, aunque en algunos países se admiten comprobaciones de la personalidad de los candidatos y de sus actitudes personales y subjetivas, que pueden desembocar en la implantación de un peligroso clientelismo político y de una desafortunada politización de la Función Pública Local. Las cosas pueden llegar a tales límites y dar lugar a tales tipos de abusos a la hora de seleccionar a los futuros funcionarios que se llegue a decir, como en Alemania Federal, que «la Administración comunal es ahora sinónimo de Administración política». $Y$ hay asimismo una obediencia demostrada, principalmente en los países del Este, en los que, cuando se evalúa al personal local, se atiende primeramente a la actitud ideopolítica, ética y moral de los aspirantes.

\section{REFERENCIA A ESPAÑA}

En el trabajo comentado no se ha incluido, lamentablemente, a nuestro país que, por lo tanto, quedó fuera de la investigación llevada a cabo por representantes de hoy paises inicialmente participantes (Bélgica, Francia, Hungría, Italia, Polonia, República Federal Alemana) a los que, en la fase posterior, se incorporaron otros (Checoslovaquia, URSS, Bulgaria, Gran Bretaña y Austria). La «geografía de la investigación» era, pues, lo suficientemente amplia y representativa como para que, a la misma, se hubiera incorporado España con lo que, sin duda, a estas alturas dispondríamos de un arsenal de datos y estadisticas comparativas muy interesantes para conocer, mejor, nuestra Función Pública Local. 
Con ello, una vez más, se comprueba la profunda nebulosa que envuelve a la Administración Local española y que determina que, de ella, conozcamos muy pocas cosas en el plano sociológico, cultural, social, financiero, burocrático, etc. De alguna manera cabría decir, con referencia a los servidores locales y utilizando una expresión muy al uso, que son como «los grandes desconocidos" y sobre los que no es fácil aproximarse con intenciones investigativas y auscultadoras. Esta situación se ha complicado en los últimos años debido a que, implantada constitucionalmente la autonomía de municipios y provincias, se han roto muchos de los vínculos que unían a unas y otros con los órganos centrales, dificultándose, de este modo, la aportación de datos para la elaboración de estadísticas actualizadas, fiables y útiles.

Las más recientes estadísticas, elaboradas conjuntamente por los Ministerios de Economía y Hacienda y para las Administraciones Púbicas arrojan, para la Administración Local, un total de personas (¿funcionarios solamente?, ¿incluido el personal laboral?, ¿contabilizados todos los empleados locales que prestan servicio en instituciones, empresas, organismos de la Administración Local?) situado entre las 160.000 y 170.000 personas (diario El País, lunes 25 de julio de 1988 , p. 43). Contingente total que, en nuestra opinión, se queda corto en los cálculos, ya que en otras estadísticas anteriores presentan cifras bastante más superiores; y es obvio que, en la última época, las Corporaciones Locales en nuestro país han generado, más o menos justificadamente lo cual ya es otra cuestión, bastante empleo especialmente para personal laboral. Baste citar como puntos de referencia, de un lado, los datos que presenta JUNOUERA GONZALEZ, según los cuales la Administración Local Española cuenta con 231.797 efectivos, de los cuales son funcionarios 174.742 y personal laboral, contratado y eventual 57.055, con exclusión, en todo caso, del personal local que trabaja en sociedades o empresas de naturaleza mercantil (JUAN JUNOUERA GONZÁLEZ, La función pública en la «Europa de los Doce», Instituto Nacional de Administración Pública, Alcalá de Henares-Madrid, 1986, p. 252). Y, de otro, los datos extraídos de la documentación del Ministerio para las Administraciones Públicas sobre cooperación local y con arreglo a los cuales, a partir de la información facilitada por la MUNPAL y el Ministerio de Trabajo y Seguridad Social, en 1985 nuestras Corporaciones Locales empleaban un total de 226.468 personas (Ministerio para las Administraciones Públicas, Dirección General de Cooperación Local, Memoria 1985 sobre Cooperación Local, p. 159).

Aparte de los aspectos meramente cuantitativos de la Función Pública Local, acabados de exponer, hay otras muchas vertientes que sería necesario conocer para alcanzar una visión global de aquélla. Sin embargo, también en dichas vertientes brilla por su ausencia una 
investigación seria, racionalizada y coherente que ayude a comprender, científicamente, a la burocracia local española. Sólo, de forma aislada, se encuentran aportaciones más o menos superficiales que inciden sobre puntos concretos, pero sin llegar a una valoración sistemática y conjunta. Así, entre otros, BAENA DEL ALCÁZAR con relación a lo que denomina "problemas estructurales» de nuestra Administración Local, escribe que, junto a los problemas organizativos, los de personal no son menores. "Las necesidades aumentan continuamente en los Municipios grandes y en los pequeños y hay que hacer frente a la fuerte competencia del Estado, ofreciendo muchas veces escasa retribución - añade- Las dificultades para encontrar técnicos son a veces muy grandes, sobre todo en los medios rurales, donde la población no deja de demandar los servicios. Con frencuencia se recurre a personal laboral, pero esto lleva a veces a una situación de inestabilidad y aumenta la carga financiera" (MARIANo BAENA del AlCÁZAR, Curso de Ciencia de la Administración, Editorial Tecnos, Madrid, 1985, p. 318). Y, más adelante, el mismo autor centrándose en la estructura municipal señala que «en cuanto al personal, en este breve apunte genérico hay que destacar dos hechos. Mientras que es crónica la falta de personal en los pequeños Municipios rurales con la inevitable secuela de la aparición de figuras anómalas (interinos, habilitados, alguaciles ejerciendo como secretarios) existen, en cambio, gravísimos problemas en los grandes municipios, donde numerosos puestos no están servidos por funcionarios profesionales $y$ es frecuente que deba recurrirse al personal laboral» (MARIANO BAENA DEL ALCÁZAR, op. cit., página 320).

La Función Pública Local se encuentra en una fase de profunda revisión con motivo de la nueva normativa que se ha dictado, en el ámbito local, en los últimos años. Problemas graves y urgentes, como el de la laboralización creciente del personal, las retribuciones, la movilidad tanto vertical como horizontal, la elaboración de nuevas relaciones de puestos de trabajo, el nuevo diseño de los funcionarios habilitados de carácter nacional, la delimitación de competencias entre Estado-Comunidades Autónomas-Corporaciones Locales, la puesta al día de los sistemas de selección, las exigencias crecientes de la cualificación profesional de los empleados locales, la implantación de nuevas técnicas de gestión para la prestación de servicios públicos, son algunos de los muchos problemas que acosan hoy a la Función Pública Local de nuestro país y que esperan soluciones imaginativas inmediatas por parte de los gestores públicos. En un Estado como el nuestro, donde es preciso conseguir el engranaje y la sincronización de todas las piezas que integran el gran sistema estatal, la solución a los problemas mencionados se torna ciertamente más conflictiva y complicada. Sin embargo, para eso está el talento de los políticos y la pericia de los administradores empeñados todos ellos 
en conseguir el difícil equilibrio de la unidad y la uniformidad en unas cuestiones y la diversidad y la multiplicidad en otras.

Algún autor ha afirmado que «en rigor, no ha existido nunca entre nosotros una Administración Local digna de tal nombre» [TOMÁSRAMÓN FERNÁNDEZ, Entre el Derecho y la Política (Escritos dispersos de un jurista independiente), El Consultor de los Ayuntamientos y de los Juzgados, Madrid, 1987, pp. 127 y 128]. Ahora, con la vigencia del texto constitucional, esta situación ha cambiado, porque la autonomía local se ha convertido en la gran palanca que debe impulsar la revitalización y potencialización de las entidades locales y, por lo mismo, de la Función Pública Local, colocándola en un proceso imprescindible de modernidad que supere tradicionales lacras y deficiencias. De ahí, pues, el interés en que los funcionarios locales sean objeto de atención por parte de sociólogos, economistas y juristas a fin de que la sociedad española conozca mejor sus rasgos diferenciales; y para que sea posible verificar comparaciones no sólo entre el funcionariado local y otros funcionariados a nivel nacional, sino también con proyección internacional.

\section{CONCLUSION}

A la vista de todo lo expuesto, surge una pregunta inexcusable: "¿Los funcionarios o agentes del escalón local de Administración forman una entidad específica irreductible a la Función Pública del Estado?».

Responder a esta interrogante exige distinguir entre dos planos. En el plano jurídico, cabe sostener que, incluso en algunos países del este europeo, la Función Pública Local goza de una escasa originalidad en cuanto a su regulación, pero que es bastante limitada, ya que, por lo general, los municipios sólo tienen capacidad para llevar a cabo ciertos actos de gestión (selección, reclutamiento, adjudicación de destinos, promoción, revocación) y las autoridades locales no están autorizadas para dictar normas sobre las condiciones de trabjo y de servicio de sus empleados. Quiere decirse, pues, que el derecho a normativizar la Función Pública Local corresponde, salvo en Gran Bretaña, al Estado, y ello en base a algunas razones: cuando está reconocida la autonomía local, el Estado central trata de evitar que los entes locales paguen mejor a sus funcionarios que lo hace la Administración del Estado respecto a los suyos; y, en el extremo contrario, la incapacidad de muchos alcaldes para atender, voluntariamente, a las reivindicaciaones y demandas del personal, sin olvidar la gran dispersión y fragmentación del «tejido municipal» que reclama medidas estatales para evitar la excesiva diversificación de regímenes y situaciones en dicho personal. 
Desde el otro plano anunciado, como es el sociológico, es evidente que, más allá de los revestimientos jurídicos unitarios o uniformizadores se ocultan peculiaridades, características y cualidades muy acusadas del personal local. Como dice el estudio en su tramo final, dichas cualidades son de doble orden: en primer término, la composición local de la Función Pública Local ofrece unos perfiles muy diferentes de los que acompañan a la Función Pública estatal, ya que el personal integrante de aquélla, como se ha venido desarrollando, cuenta con mayor porcentaje de mujeres, es de mayor edad, está menos cualificado, trabaja con más frecuencia a tiempo parcial, etc., $y$, en segundo lugar, se advierte una mayor aproximación del funcionario local respecto a los estamentos y niveles políticos. 
REALA-1988, núm. 240. GONZALEZ-HABA GUISADO, VICENTE MARIA. LA FUNCION PUBLICA L...

REALA-1988, núm. 240. GONZALEZ-HABA GUISADO, VICENTE MARIA. LA FUNCION PUBLICA L... 